TAO, Vol. 15, No. 5, I-II, December 2004

\title{
Preface to the Special Issue on Asian Dust Storms and Effects on Taiwan
}

\author{
Shaw Chen Liu
}

\section{PREFACE}

Asian dust storms are frequently observed over the western Pacific in the spring. Although the bulk of the dust storms travel eastward to Japan and the North Pacific, many of them reach Taiwan. This is particularly the case when there is a winter northeasterly monsoon, which brings Asian continental outflow to the East China Sea and turns toward Taiwan and the South China Sea under the influence of the Siberian high. As a result, the dust storm is frequently associated with long-range transport of air pollutants. The environmental issues of the dust storms and long-range transport of air pollutants are the major subject of this special issue.

This special issue includes a total of fourteen papers. The first paper (Lin et al.) presents a comprehensive analysis of the major characteristics of Asian dust storms and long-range transport of air pollutants. In addition, a quantitative evaluation of the impact on the air quality in Taiwan is presented. In the second paper, Chen and Wann report on the inputs of metals from Asian dust storms to the sediment column of a seasonally anoxic high elevation lake in Taiwan. The third paper (Chiamg et al.) discusses lidar observations of the dust storms in spring 2002. In the following paper, Liu and Lin discuss the potential of real-time monitoring and forecast of the Asian dust storm by using observations on the geostationary satellite GMS-5. This is followed by five papers on the compositions of aerosols observed at various stations in and around Taiwan during the dust storm season: Wang et al. at the northern tip of Taiwan (windward to the dust storms); Yuan et al. at an island in the Taiwan strait; Chou et al., Lung et al., and Hsu et al. are at an urban station (Taipei) in northern Taiwan. Significant impacts of the dust storms have been found at all three stations on not only crustal materials but also air pollutants. The tenth paper (Chen et al.) presents model simulations of dust storms occurred in East Asia during the springs of 2002 and 2003. Liu and Hsiao compare the composite characteristics of dust storms affecting Beijing vs. those reaching Taipei. C. Liu et al. present the composite synoptic features of the atmosphere in active dust storm years and compare to those of inactive dust storm years. It is followed by J. Liu et al. $\left(13^{\text {th }}\right)$ paper which presents results from an analysis of a severe dust storm induced by an intensive cyclogenesis in Mongolia. Last but certainly not the least, Lee and Liu present a conceptual framework on information, impacts and policymaking for Taiwan on the Asian dust storms.

The majority of the papers include findings and results from research projects sponsored in part by the Taiwan Environmental Protection Administration through grants on the "Asian Dust Storms and Their Impacts on Taiwan", and by a grant from Academia Sinica under theme project "Particulate Matter and its Environmental Impact in Taiwan". Their supports are gratefully acknowledged. 


\section{Guest Editor:}

Shaw Chen Liu

Research Center for Environmental Changes

Academia Sinica, Taipei, Taiwan

E-mail: shawliu@rcec.sinica.edu.tw 